\title{
Examining Bus Lost Time Dynamics for a Bus Rapid Transit Station
}

\author{
Ankit Kathuria and M. Parida \\ Indian Institute of Technology Roorkee \\ Ch. Ravi Sekhar \\ Central Road Research Institute (CSIR), India \\ Manu Pathak \\ Centre of Environment Planning and Technology, India
}

\begin{abstract}
Bus Rapid Transit (BRT) systems are considered to be the most effective alternative for solving urban transportation problems for both developed and developing countries. The conventional approach to estimate dwell time (DT) is based on traditional DT models derived for normal bus stops, but not for modern BRT stations. BRT stations are different from bus stops in terms of length of platform, multiple loading areas, and number of passengers handled. Therefore, understanding dwell time dynamics, including the recently-introduced component of Bus Lost Time (BLT), is important to improve the operations of BRT systems. This research introduces various possible scenarios of alighting and boarding using video data collected at the Shiuranjini BRT station in Ahmedabad, India.

In total, 877 observations of BLT and DT were extracted from 17 hours of video data recorded for one full-service time of the day. The possibility of BLT occurrence was examined and explained with the help of conceptual line diagrams, and the probability distribution of BLT was fitted for two loading area platforms by considering 401 observations from the BRT platform video data of the entire service period. A comparative evaluation was made between observed and estimated BLT values. This study estimated station capacities before and after, including BLT as a DT component to observe the effect of BLT on BRT stop capacity. It was observed from the results that including BLT in dwell time reduced BRT capacity by $11 \%$. This study provides ready-touse BLT values for correct estimation of dwell time, thus improving accurate estimation of BRT station capacity.
\end{abstract}

Keywords: Bus rapid transit, BRT, bus lost time, bus lost time dynamics 


\section{Introduction}

A large number of cities in the world are facing rapid urbanization and development, which is leading to increased demand for travel by private modes and resulting in congestion (Zimmerman and Agarwal 2012). Light rail transit (LRT) and mass rapid transit systems (MRTS) are two high-investment public transport alternatives for significantly reducing congestion on roads. Bus Rapid Transit (BRT) systems are becoming popular all over the world because of their low initial investment (Gupta 2014; Carey 2002)). They are considered to be reliable, cheap, and effective and regarded as a widespread option for public transportation (Jiang et al. 2012). Satiennam et al. (2013) identified BRT as a system that can bring about a modal shift from private vehicles. Currie (2005) reported BRT to be as effective as a rail system in generating patronage when developed to replace conventional bus service. Deng and Nelson (2011) reported the acceptance and popularity of BRT, which has increased attractiveness because it is an integrated system of facilities, amenities, services, intelligent transportation systems (ITS), and operations (Levinson et al. 2002). Vuchic (2002) conducted a comparison between bus semi-rapid transit and LRT and found out that the former is better in terms of initial investment and implementation time.

Although not quite a decade old in India, BRT systems are running in eight cities of India. Therefore, understanding system capacity and its components is now becoming very crucial. One of the major components of BRT system capacity is dwell time (DT).

The traditional approach of estimating bus DT at a stop based on the number of passengers alighting and boarding is considered to be suitable for analysis of a suburban stop with a single marked bus loading area but not for a modern BRT station (Jaiswal et al. 2010). There are two commonly-adopted methods of DT estimation. One lengthy method is by field measurement, and the other, relatively less time-consuming method (used by planners) is by using already-available average per-passenger service time values, as indicated in the literature. Large amounts of time and money are involved in the field measurement method; therefore, planners use the second method, which requires the number of passengers boarding and alighting per bus in a station and the per-passenger alighting and boarding times. However, the problem here is that these default per-passenger service time values are estimated and reported (using regression models) for conventional bus stops (Guenthner and Hamat 1988; Levinson 1983). These conventional bus stops have negligible bus lost time (BLT) because the characteristics of a bus stop are different from a modern BRT station (Jaiswal et. al. 2010). According to the Transit Capacity and Quality of Service Manual (TCQSM) (Transportation Research Board [TRB] 2013), BLT is defined as the "waiting time for bus, between when the bus comes to stop in its loading area and when the first passenger boards." The average walking time for a passenger in a BRT station with multiple loading areas is more than that for a normal bus stop because of the long length of the platforms and more crowding (Jaiswal et al. 2010). Therefore, if the default per-passenger service time (from the regression model) of a normal bus stop is used in the DT estimation of a BRT station, then these values will underestimate the DT because negligible BLT would be included. Therefore, there is a need to add BLT to DT separately to take into account the 
increased walking time in a BRT station. This concept with a model has been approved and include in the TCQSM, as shown in the literature.

The main objective of this research was to improve the estimation of DT by examining the dynamics of boarding and alighting (B\&A) of single-door buses. The concept of BLT as a recently-introduced component of DT in the TCQSM was then studied for various scenarios of B\&A occurring in series and simultaneously. Data from the busiest bus stops of the Ahmedabad BRT system in India were considered to examine the dynamics of DT. BLT values for two loading areas were included in the study, and the loading area capacity of stations was estimated before and after considering BLT.

\section{Review on Estimation of Dwell Time and Its Components}

In the literature, most studies consider linear regression models for DT estimation, and the main parameter considered in these models is the number of $B \& A$ passengers (Feder 1973; Levinson 1983; Guenthner and Hamat 1988). Previous researchers (Levinson 1983) estimated DT for buses and derived that it depended on two primary factorsnumber of passengers boarding and alighting and time required for the bus doors to open and close. This is shown in Equation 1:

$$
\mathrm{DT}=\mathrm{tN}+\mathrm{t}_{\mathrm{oc}}
$$

where DT is the dwell time, $t$ is the average $B \& A$ time per passenger (reported to be 2.75 $\mathrm{sec}), \mathrm{N}$ is the total number of persons boarding and alighting, and $\mathrm{t}_{\mathrm{oc}}$ is the bus door opening and closing time. Another DT model was proposed by Guenthner and Sinha (1983), as shown in Equation 2:

$$
\frac{\mathrm{DT}}{\text { Total }}=5.0-1.2 \ln (\text { Total })
$$

where DT is the dwell time and Total is the total number of passengers boarding and alighting.

Based on field observations, a link between DT estimation and fare collection systems was deduced for buses (Guenthner and Sinha 1983), which reported the average alighting and boarding time per passenger as $1.81 \mathrm{sec}$ and $5.66 \mathrm{sec}$, respectively, considering 10 different types of fare collection systems. Lin and Wilson (1992) reported DT models for one- and two-car trains and reported average alighting and boarding time per passenger as $0.23-1.4 \mathrm{sec}$ and average boarding time per passenger as $0.27-1.15$ sec. Levin and Torng (1994) examined relationships between low-floor buses and DT, and a Transit Cooperative Research Program (TCRP) study (1996) relates DT savings to the layout of bus stops. Duekar et al. (2004) analyzed dwell times with respect to bus door widths, and Li et al. (1971) formulated a model to study DT based on preferences of doors among passengers. Rajbhandari et al. (2003) studied DT on a large data set obtained by Automatic Vehicle Location (AVL) data, and Tirachini (2013) studied techniques for payment of fares to reduce DT in buses. Curie et al. (2013) studied the effects of crowding and its influence on dwell times, and TRB $(2003,2013)$, Vuchic 
(2005), and Sun et al. (2014) developed a model for DT estimation, as presented in Equation 3:

$$
\mathrm{DT}=\mathrm{P}_{\mathrm{a}} \mathrm{t}_{\mathrm{a}}+\mathrm{P}_{\mathrm{b}} \mathrm{t}_{\mathrm{b}}+\mathrm{t}_{\mathrm{oc}}
$$

where DT is dwell time, $\mathrm{P}_{\mathrm{b}}$ and $\mathrm{P}_{\mathrm{a}}$ are the number of passengers boarding and alighting, $t_{a}$ and $t_{b}$ are the per-person alighting and boarding times, and $t_{o c}$ is the bus door opening and closing time. Because this model is applicable only when B\&A are occurring in series, a different DT model for simultaneously-occurring B\&A was reported in the literature, as presented in Equation 4 (Sun et al. 2014; Ashtiani and Iravani 2002; Larrain and Munoz 2008):

$$
\mathrm{DT}=\max \left\{\mathrm{P}_{\mathrm{a}} \mathrm{t}_{\mathrm{a}}, \mathrm{P}_{\mathrm{b}} \mathrm{t}_{\mathrm{b}}\right\}+\mathrm{t}_{\mathrm{oc}}
$$

BLT was introduced as a new component of DT. TRB (2013) and Jaiswal et al. (2010) explain loss of station capacity due to BLT, and Jaiswal et al. (2010) reported BLT values for three linear loading areas for a BRT system in Brisbane, Australia. The proposed DT equation including BLT is mathematically expressed in Equation 5. An average of $4 \mathrm{sec}$ of BLT is reported for three loading areas (TRB 2013):

$$
\mathrm{DT}=\mathrm{P}_{\mathrm{a}} \mathrm{t}_{\mathrm{a}}+\mathrm{P}_{\mathrm{b}} \mathrm{t}_{\mathrm{b}}+\mathrm{t}_{\mathrm{oc}}+\text { BLT }
$$

The literature summarizes various equations that were improved with time to estimate DT for both in-series and simultaneously-occurring B\&A. The aforementioned DT equations including BLT are not understood based on different scenarios of $B \& A$; in some scenarios, using the same equation might overestimate or underestimate DT. The literature reports an average BLT value for only three loading areas, but no values were reported for two or four loading areas. These values play an important role in estimating overall system capacity.

\section{Methodology Development}

Methods of B\&A play a major role in estimating DT. Three ways are most commonly observed, namely, boarding and alighting from the front and back doors, alighting from the front door and boarding from the rear door, and boarding and alighting from a single door. The concept of $B \& A$ is briefly discussed in the following subsections.

\section{BLT Dynamics for In-Series B\&A}

Four different scenarios to estimate dwell time $\left(T_{0}\right)$ in which in-series $B \& A$ takes place are illustrated in Figure1. In the scenario a), alighting occurs before boarding, and in series b), boarding occurs before alighting. Further, in scenarios c) and d), either alighting or only boarding takes place. The main components for estimating DT are total alighting time $\left(T_{a}\right)$, boarding times $\left(T_{b}\right)$, bus lost time (BLT), and bus door opening and closing time $\left(t_{o}\right.$ and $\left.t_{c}\right)$, as represented in Figure 1. 
FIGURE 1.

Scenarios of B\&A occurring

in a series

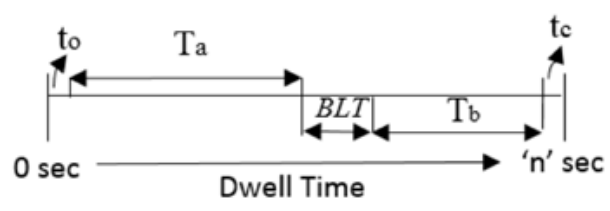

a) First $\mathrm{A}$ and then $\mathrm{B}$

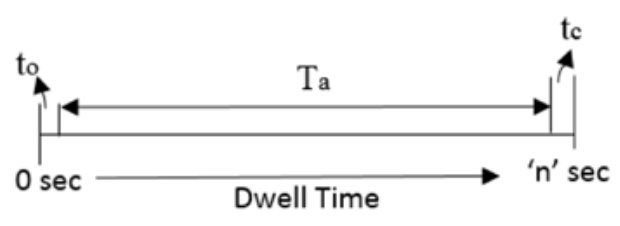

c) Only A

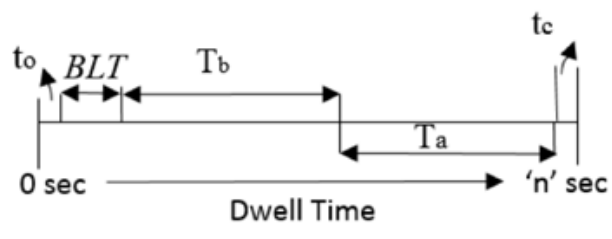

b) First B and then A

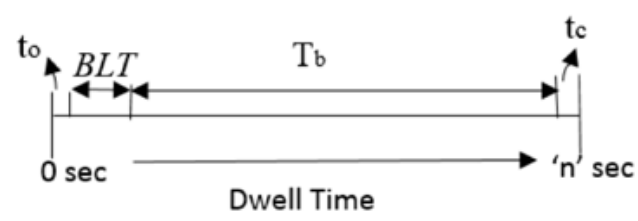

d) Only B

The TCQSM (TRB 2013) provides the following equation for estimation of DT for all these cases:

$$
\mathrm{DT}=\mathrm{P}_{\mathrm{a}} \mathrm{t}_{\mathrm{a}}+\mathrm{P}_{\mathrm{b}} \mathrm{t}_{\mathrm{b}}+\mathrm{t}_{\mathrm{oc}}+\mathrm{BLT}
$$

where DT is the dwell time, $P_{b}$ and $P_{a}$ are the number of passengers boarding and alighting, $t_{a}$ and $t_{b}$ are per-person alighting and boarding times, and $t_{o c}$ is the bus door opening and closing time. BLT was initially introduced by Jaiswal et al. (2010) and was considered further in the TCQSM (TRB 2013). Using the definition of BLT, scenarios a), b), and d) in Figure 1 will have BLT; in scenario c), BLT will not occur, as in this scenario, no boarding is taking place.

\section{BLT Dynamics for Simultaneously-Occurring B\&A}

Eight different scenarios in which B\&A occur simultaneously are presented in Figure 2. Here, $T_{a}$ is total time of alighting passengers, and $T_{b}$ is total time of boarding passengers. In scenario a), first alighting starts, and then boarding starts in between alightings; in scenario e), first boarding starts, and then alighting starts in between. In these scenarios, both boarding and alighting end at the same time. Scenario a) will not have any BLT because the first passenger will board the bus while alighting is occurring. On the other hand, scenario e) will have added BLT because the alighting is starting when few passengers have already boarded the bus. Hence, the BLT-the time taken by the first passenger to board the bus-will not overlap with the alighting time. In scenario b), boarding starts with alighting but ends before alighting; similarly, in scenario f), boarding starts with alighting, but ends before alighting. In both the scenarios, there will be no BLT, as both boarding and alighting start in parallel. Further, in scenario c), alighting starts before boarding and ends after boarding; in scenario g), boarding starts before alighting and ends after alighting; hence, BLT will exist in this condition. Finally, in scenarios d) and h), alighting starts before boarding and vice versa. In scenario h), BLT will be observed, as boarding is occurring before alighting and is not starting in parallel with alighting. 
FIGURE 2.

Scenarios of B\&A occurring simultaneously
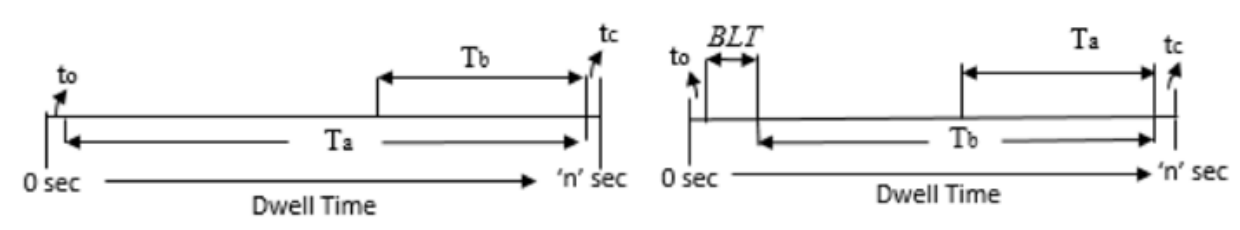

a) First A starts and then B starts in between and ends with $\mathrm{A}$

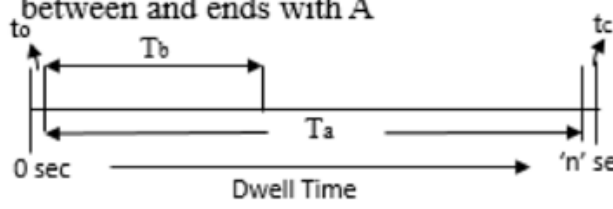

e) First B starts and then A starts in between and ends with $B$

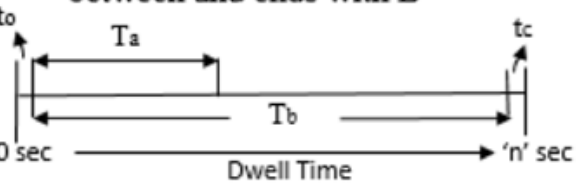

b) A starts with $B$ and ends after $B$

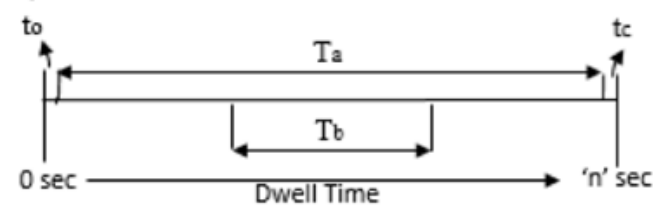

f) B starts with $A$ and ends after $A$

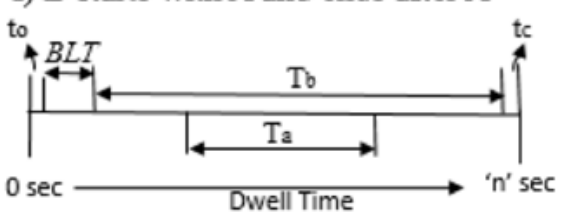

c) A starts before $B$ and ends after B

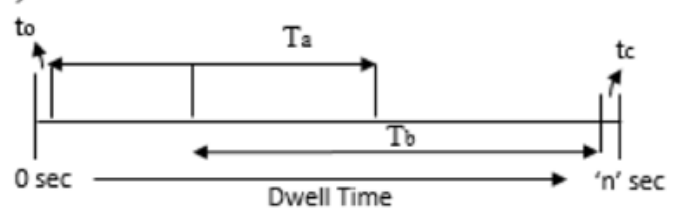

d) A starts before B and ends before B g) B starts before $\mathrm{A}$ and ends after $\mathrm{A}$

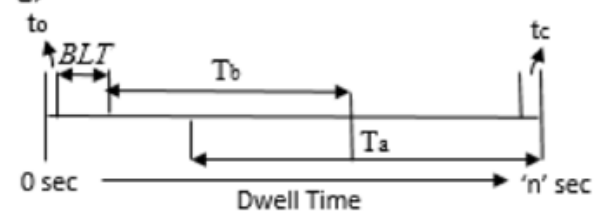

h) B starts before $A$ and ends before $A$

It is noteworthy that the TCQSM (TRB 2013) suggests considering a BLT value of 4-4.5 sec for all scenarios of DT for three loading areas, but it does not explain in which scenarios it should be considered. Therefore, based on this research, it is recommended that BLT be considered only for a few of the aforementioned scenarios. These BLT values are then used for DT estimation from the videography data in Equation 6 for in-series $B \& A$ and in an improved Equation 7 for simultaneously-occurring $B \& A$ :

$$
\mathrm{DT}=\max \left\{\mathrm{P}_{\mathrm{a}} \mathrm{t}_{\mathrm{a}}, \mathrm{P}_{\mathrm{b}} \mathrm{t}_{\mathrm{b}}\right\}+\mathrm{BLT}+\mathrm{t}_{\mathrm{oc}}
$$

After understanding all the scenarios and the gap in the application of BLT, a modified definition of BLT is suggested-BLT is the time lost by a bus between when it stops and when the first passenger boards, given that this time does not overlap with the alighting time and bus door opening time. This improvement in the definition is necessary because directly adding the time taken by the first passenger to board the bus in the DT estimation without observing if it is overlapping with alighting time will overestimate DT.

\section{Study Area and Data Collection}

\section{Study Area}

In this study, the Ahmedabad BRT system was considered. This system started functioning in 2009 and is a closed BRT system with the following features: 
- Entry of passengers to station supported by well-defined pedestrian mid-block crossing

- Broad single-door buses with level boarding and alighting

- Pre-board fare collection system using smartcards

- Segregated busways on majority of network length

- Location of bus station and busway on median

- Good integration of network of routes and corridors

- BRT stations that are covered, secure, comfortable, and protected from different kinds of weather

- Integration with feeder services

- Restricted entry to any other kind of bus rather than that prescribed

- Distinctive marketing identity comparable to MRT systems

These features satisfy it being called a closed BRT system (Mahadevia et al. 2012). The existing Ahmedabad BRT network is around $88.5 \mathrm{kms}$ with 127 BRT stations and 12 routes. Of the 127 stations, the Shivranjini BRT station was selected to study DT dynamics because it is one of the busiest stops; most major routes pass through this station, and dense commercial land use is observed around the station and on both the sides of the road. The BRT network and the physical characteristics and inside view of the bus station are shown in Figure 3. From the figure, it can be observed that the Shivranjini station has two linear loading areas for both directions (up/down).

FIGURE 3.

Ahmedabad BRT network and location and view of Shivranjini station

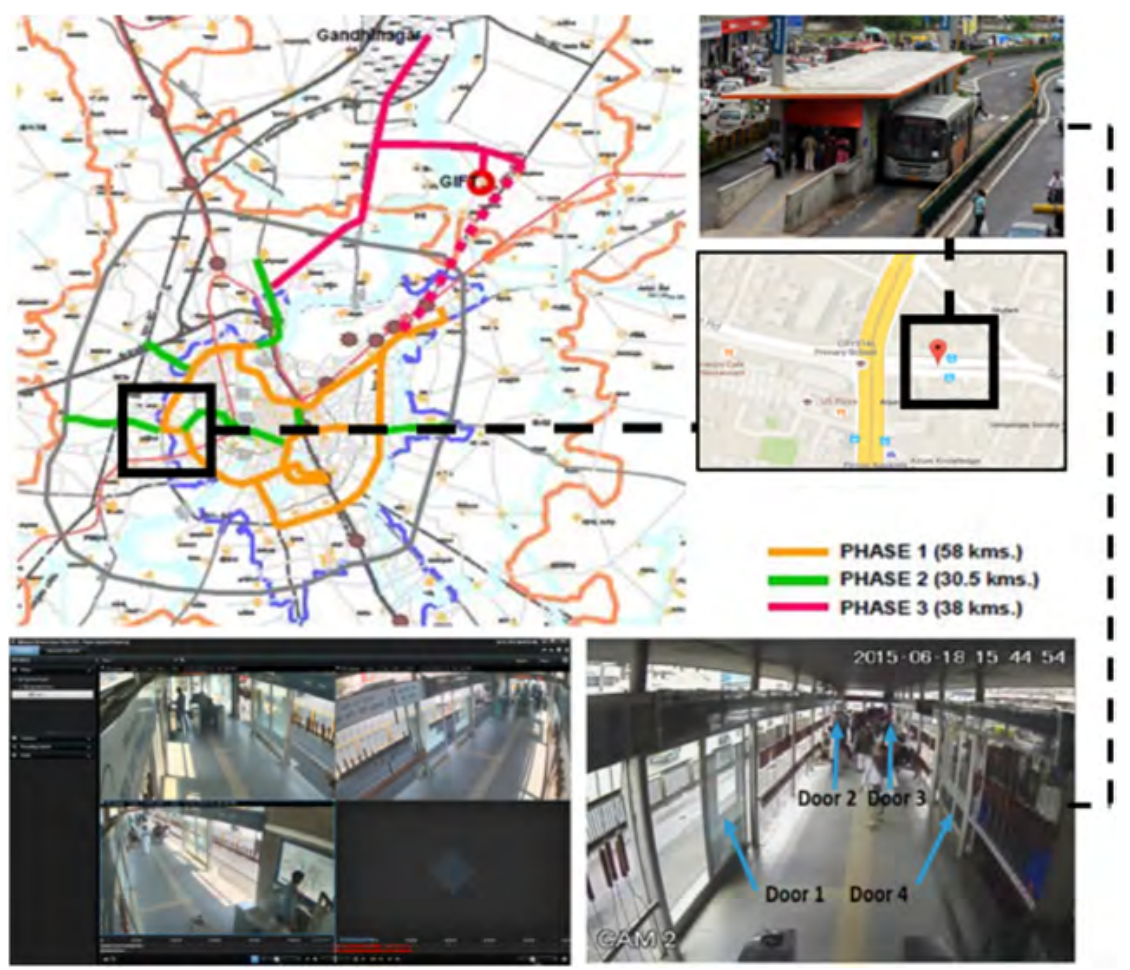




\section{Data Collection}

Ahmedabad Janmarg Limited (AJL) monitors the total BRT system with the help of integrated GPS and GIS-based ITS techniques. In this study, video data collected by a BRT cell of AJL were considered. There were three closed-circuit televisions (CCTVs) installed in the station to capture the B\&A on all four doors (see Figure 3). Of the three CCTVs, two were installed at the entry/exit doors of the station and one in the middle of the station. The operation and data management of CCTV are managed by Milestone Xprotect Video Management software, in which videos are recorded and saved to a digital video recorder (DVR) installed at the station. Video data were extracted for one working day (June 18, 2015) at the Shivranjini platform for a complete service period from 6:00 AM to 11:00 PM (0600-2300) using Klite software, including:

- Time when bus comes to a complete stop

- Bus door-opening time-stamp

- Time when first and last passengers board and alight bus

- Number of passengers boarding and alighting

- Time taken by first passenger to board

- Bus door-closing time-stamp

\section{Passenger Behavior while Waiting at Two Loading BRT Stations}

Figure 4 demonstrates waiting pattern of passengers at two loading areas of a BRT station. Passengers waiting at the platform stand more towards loading area 1 than loading area 2 , as shown by the shaded portion with centroid $y-y$. The distances $d 1$ and $\mathrm{d} 2$ are the distances of the bus doors at LA 1 and LA 2, respectively, from the centroid $y-y$ of the shaded portion. For most cases, $d 1$ would be less than $d 2$ because the walking time of passengers to the bus door in loading area 1 would be less. Therefore, in the best-case scenario, the lost time would be less for loading area 1 and more for loading area 2. Also, passengers walking towards the bus door at loading area 1 would walk along the direction of the bus, but passengers walking towards the bus door at loading area 2 would walk against the direction of the bus. This overlap of time would cause a reduction in lost time for loading area 1.

FIGURE 4.

Waiting pattern and distance of bus door to loading area

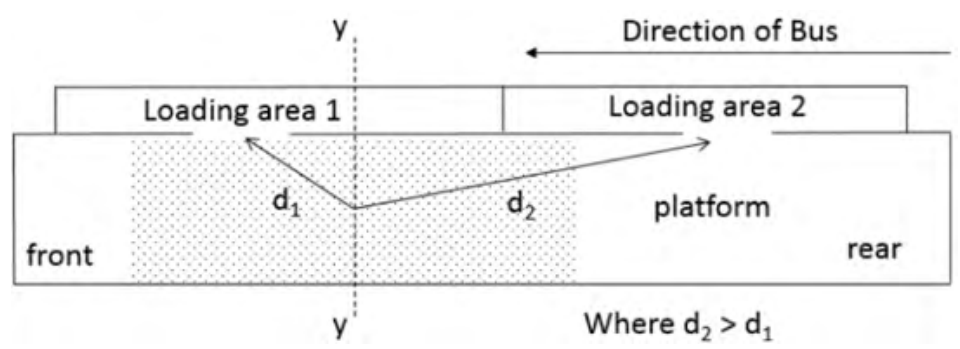

\section{Estimation of BLT}

BLT will be considered as a DT component only when either boarding occurs before alighting, boarding occurs after alighting (in a series), or only boarding is occurring 
(as was shown in Figures 1 and 2). Observed BLT data were fitted by considering standard probability distributions. The observed and fitted probability and cumulative probability distributions for BLT data of loading areas 1 and 2 of the entire service period (0600-2300) are presented in Figure 5.

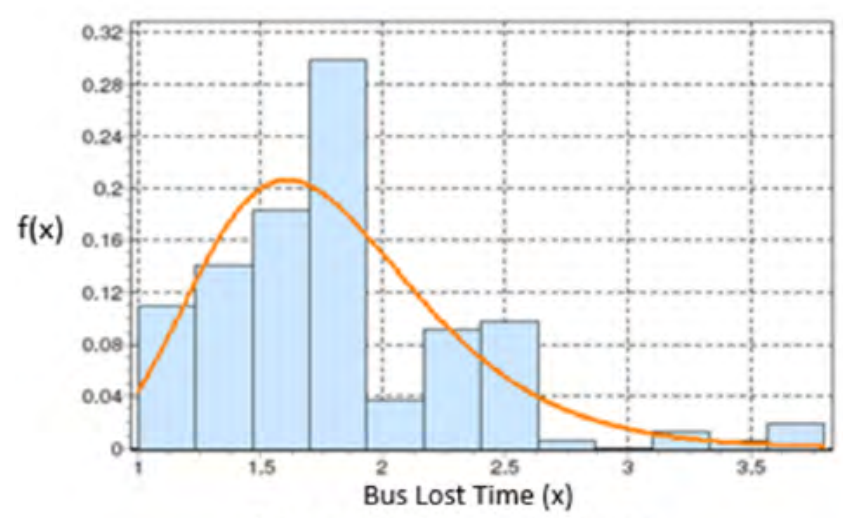

a) BLT Distribution Loading Area 1

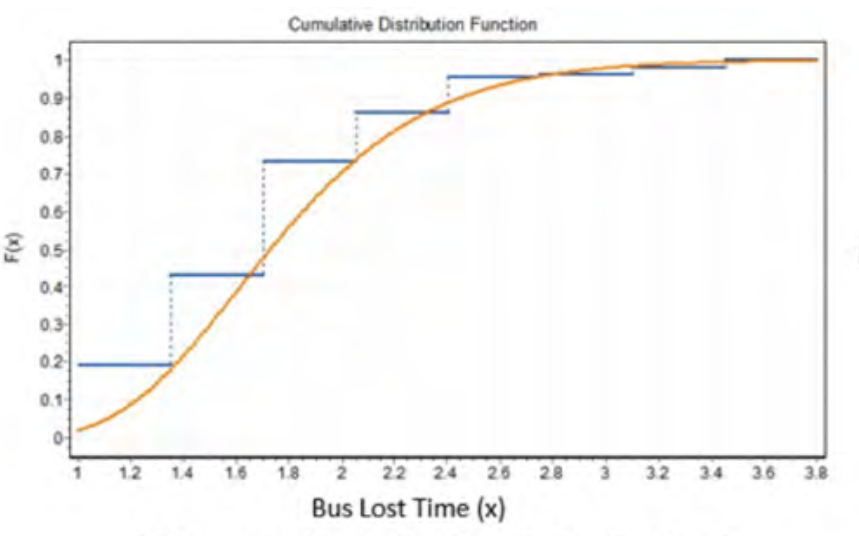

b) Cumulative Distribution Curve for Loading Area 1

(a) Fitted distribution and cumulative probability distribution of BLT for loading area 1

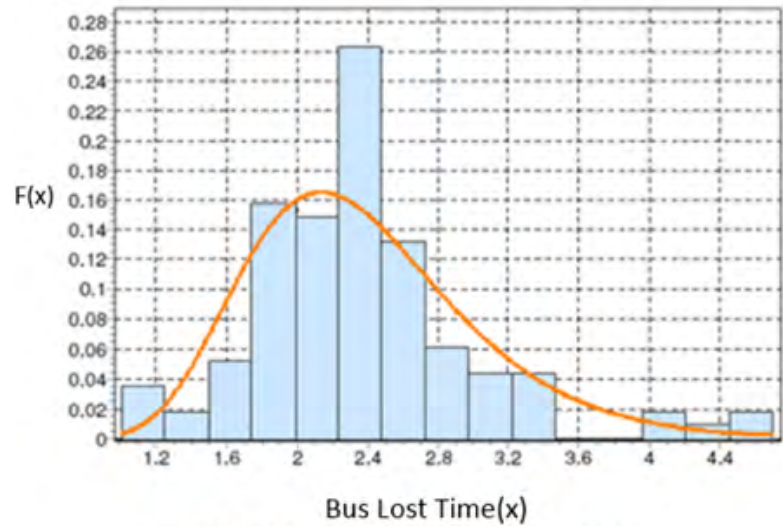

a) BLT Distribution of Loading Area 2

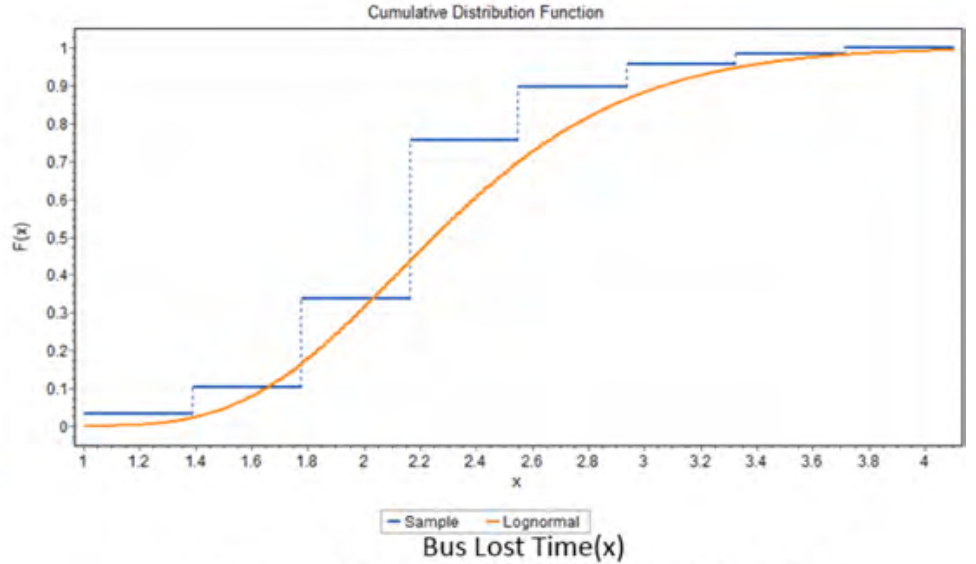

b) Cumulative Distribution Curve for Loading Area 2

(b) Fitted distribution and cumulative probability distribution of BLT for loading area 2

FIGURE 5. Fitted distribution and cumulative probability distribution of BLT

For loading areas 1 and 2, a lognormal distribution function fits best. For the total data set, BLT values for loading areas 1 and 2 were analyzed. The fitted probability distribution was validated statistically by considering goodness of fit measures such as KS and Chi-square tests. The significance of estimated values are presented in Table 1. These values are less than the critical values at a $5 \%$ level of significance. The significance 
values of the $\mathrm{KS}$ and Chi square tests suggest that BLT during the day follows a lognormal distribution.

TABLE 1.

Distribution Fitting Significance Values

\begin{tabular}{|c|c|c|c|c|c|}
\hline & \multirow[t]{2}{*}{$\begin{array}{l}\text { Time } \\
\text { Period }\end{array}$} & \multirow[t]{2}{*}{$\begin{array}{c}\text { Loading } \\
\text { Area } \\
\text { (LA) }\end{array}$} & \multirow[t]{2}{*}{$\begin{array}{l}\text { Sample } \\
\text { Size }\end{array}$} & $\begin{array}{c}\text { KS Test } \\
\text { Significance }\end{array}$ & $\begin{array}{c}\text { Chi- Square } \\
\text { Test } \\
\text { Significance }\end{array}$ \\
\hline & & & & Lognormal & Lognormal \\
\hline \multirow{2}{*}{ Total Service Period } & \multirow{2}{*}{$0600-2300$} & LA 1 & 212 & 0.11 & 0.19 \\
\hline & & LA 2 & 189 & 0.05 & 0.06 \\
\hline \multirow{2}{*}{ Morning Peak } & \multirow{2}{*}{$1000-1100$} & LA 1 & 35 & 0.21 & 0.21 \\
\hline & & LA 2 & 26 & 0.71 & 0.46 \\
\hline \multirow{2}{*}{ Off-Peak } & \multirow{2}{*}{$1400-1500$} & LA 1 & 23 & 0.28 & 0.47 \\
\hline & & LA 2 & 22 & 0.21 & 0.23 \\
\hline \multirow{2}{*}{ Evening Peak } & \multirow{2}{*}{$1700-1800$} & LA 1 & 33 & 0.23 & 0.65 \\
\hline & & LA 2 & 28 & 0.22 & 0.70 \\
\hline
\end{tabular}

The average BLT value during the off-peak hour was more than both the morning and evening peak hours because during less crowded times, passengers tend to stand between loading areas 1 and 2 rather than near to the gate of loading area 1 . The descriptive statistics of BLT for the entire service period, off-peak hour, and peak hours is presented in Table 2 . These values are compared with the fitted distribution. It can be observed from the Table 2 that the average BLT values of loading areas 1 and 2 vary from 1.8 to 2.6 seconds, respectively, throughout the day.

TABLE 2.

\begin{tabular}{|c|c|c|c|c|c|c|c|c|c|}
\hline \multirow[t]{2}{*}{$\begin{array}{c}\text { Loading } \\
\text { Area }\end{array}$} & & \multicolumn{2}{|c|}{$\begin{array}{c}\text { BLT } \\
(0600-2300)\end{array}$} & \multicolumn{2}{|c|}{$\begin{array}{c}\text { BLT } \\
\text { Morning Peak } \\
(1000-1100)\end{array}$} & \multicolumn{2}{|c|}{$\begin{array}{c}\text { BLT } \\
\text { Off-Peak } \\
(1400-1500)\end{array}$} & \multicolumn{2}{|c|}{$\begin{array}{c}\text { BLT } \\
\text { Evening Peak } \\
(1800-1900)\end{array}$} \\
\hline & & Obs. & Est. & Obs. & Est. & Obs. & Est. & Obs & Est. \\
\hline \multirow{4}{*}{ LA1 } & Sample Size & 212 & 212 & 35 & 35 & 23 & 23 & 33 & 33 \\
\hline & Mean(sec) & 1.8 & 1.8 & 1.2 & 1.1 & 2.0 & 2.0 & 1.7 & 1.7 \\
\hline & 85th Percentile (sec) & 2.1 & 2.3 & 1.3 & 1.5 & 2.3 & 2.4 & 2.0 & 2.0 \\
\hline & Std Dev (sec) & 0.6 & 0.5 & 0.5 & 0.5 & 0.5 & 0.4 & 0.2 & 0.2 \\
\hline \multirow{4}{*}{ LA 2} & Sample Size & 189 & 189 & 26 & 26 & 22 & 22 & 28 & 28 \\
\hline & Mean (sec) & 2.4 & 2.3 & 1.5 & 1.5 & 2.6 & 2.6 & 2.2 & 2.2 \\
\hline & 85th Percentile(sec) & 2.7 & 3.0 & 1.7 & 1.9 & 3.2 & 3.1 & 2.6 & 2.8 \\
\hline & Std Dev (sec) & 0.6 & 0.6 & 0.2 & 0.1 & 0.4 & 0.4 & 0.5 & 0.5 \\
\hline
\end{tabular}

Further, to observe the effect of geometric design of a BRT station, the BLT value of the two loading areas was compared with a study done for the Brisbane BRT system for three loading areas. The results were compared to show different BLT values with changes in geometric design in terms of number of loading areas. Comparing different geometric designs in terms of 85th percentile BLT for two and three loading areas of a BRT station, the following results were observed (Table 3). 
TABLE 3.

Comparison of BLT Values for Different Geometric Designs
LA-1 (sec) $\quad$ LA-2 (sec) $\quad$ LA-3 (sec)

Mater Hill Busway Station, Brisbane, Australia

BLT (3 loading areas)

Shivranjini BRT Station, Ahmedabad, India

BLT (2 loading areas)

2.3

3.0

The above two results show that the BLT for three loading areas of a BRT station is higher for all loading areas. In this BRT station, passengers prefer standing near to the second loading area so they have an equal distance to walk towards both the first and third loading areas; therefore, the time taken by the first passenger to board the bus in the first and third loading areas is higher than the second loading area. On the other hand, for two loading areas in a BRT station, the BLT of loading area 1 is less than that of loading area 2 because the passengers stand closer to loading area 1. Overall, the BLT of a station with two loading areas is less than that with three loading areas because of the longer station length and crowding.

\section{Rule of Thumb for Considering BLT}

Viewing videos to observe the scenarios is a lengthy process; therefore, a rule of thumb for adding BLT was proposed in the present research based on closely observing 877 scenarios from the video data. It was determined from the observed data that in all scenarios in which BLT was occurring, $94 \%$ had critical boarding passengers, as follows:

1. Only boarding passengers (no alighting passengers)

2. Number of boarding passengers $>$ number of alighting passengers

For all other scenarios in which BLT was not occurring, $91 \%$ had either critical alighting or the number of boarding passengers was equal to number of alighting passengers. Therefore, BLT can be added to the DT data of stations at which boarding is critical.

\section{Capacity Estimation}

The importance of BLT is explained through bus station capacity estimation. Bus stop capacities were estimated with and without considering BLT. The capacity estimation of a BRT station is determined by using Equation 8 (TRB 2013):

$$
B_{n}=\frac{3600\left(\frac{g}{c}\right)}{t_{c}+D T_{n}\left(\frac{g}{c}\right)+z C_{v}\left(D T_{n}\right)}
$$

where $B_{n}$ is the capacity of $n$th loading area (bus/hr), 3,600 is the number of seconds in 1 hour, $\mathrm{g} / \mathrm{C}$ is the green time ratio, $\mathrm{z}$ is the standard normal variable corresponding to $\mathrm{a}$ desired failure rate, $t_{c}$ is clearance time, and $C_{v}$ is the coefficient of variation of DT. For estimation of capacity, standard values of parameters as given in the TCQSM (TRB 2013) were considered, leaving the coefficient of variation and DT, which were calculated using data. Therefore, the green time ratio $(\mathrm{g} / \mathrm{c}$ ) was taken as 1 (assuming an unsignalized lane and bus facility), $t_{c}$ as $10 \mathrm{sec}$, and a standard normal value ( $\mathrm{z}$ ) of 1.28 , considering a $10 \%$ failure rate for both the loading areas. Using the video extracted data, the $C_{v}$ values with and without considering BLT were estimated for loading areas 1 and 2 . These value 
were estimated using 877 observation of DT that extracted for different scenarios of $B \& A$ from the BRT station video. Average DT values also were estimated considering the same data.

From Table 4, it can be observed that considering BLT resulted in increased average DT of $13 \%$ for loading area 1 and $15 \%$ for loading area 2 , whereas the bus stop capacity was reduced by $11 \%$. Therefore, not considering BLT will always lean towards an inflated value of capacity. Again, BLT should be considered only for certain scenarios of B\&A.

TABLE 4.

\begin{tabular}{|c|c|c|c|c|c|}
\hline \multirow{2}{*}{ Lost Time } & \multicolumn{2}{|c|}{$C_{v}$ of Dwell Time } & \multicolumn{2}{|c|}{ Average Bus Dwell Time(sec) } & \multirow{2}{*}{$\begin{array}{l}\text { Bus Stop } \\
\text { Capacity } \\
\text { (buses/hr) }\end{array}$} \\
\hline & Loading Area 1 & Loading Area 2 & Loading Area 1 & Loading Area 2 & \\
\hline Without BLT & 0.40 & 0.43 & 14.8 & 16.7 & 185 \\
\hline Including BLT & 0.35 & 0.37 & 17.1 & 19.7 & 164 \\
\hline$\%$ Change & $13 \%$ & $14 \%$ & $13 \%$ & $15 \%$ & $11 \%$ \\
\hline
\end{tabular}

\section{Conclusions}

Understanding DT components and the related dynamics is useful for estimating system capacity of BRT in a structured manner. The main findings of the study are as follows:

- BLT is defined as the waiting time for a bus between when it comes to stop in its loading area and when the first passenger boards (TRB 2013).

- BLT should be considered for DT estimation only for 6 types of B\&A scenarios out of total 12 possible scenarios. Adding BLT as a DT component to all other scenarios will result in overestimation of DT.

- The six scenarios in which BLT will occur are scenarios a), b), and d) for in-series $B \& A$ (Figure 1) and scenarios e), g), and $h$ ) for simultaneously-occurring $B \& A$ (Figure 2).

- A modified definition of BLT is suggested in this paper: BLT is the time lost by a bus between when it stops and when the first passenger boards, given that this time does not overlap with the alighting time and the bus door opening time.

- BLT values were estimated, and it was observed that the mean BLT values during the off-peak period are more than during the morning and evening peaks. Also, the average BLT of loading area 2 is more than that of loading area 1.

- BLT data followed lognormal distribution for both loading areas 1 and 2 .

- This research suggests a BLT value of $2.3 \mathrm{sec}$ for loading area 1 and $3.0 \mathrm{sec}$ for loading area 2.

- Considering BLT as a DT component resulted in an approximately $13 \%$ and $15 \%$ increase in average DT for loading areas 1 and 2, respectively, and the bus stop capacity was reduced by $11 \%$. Therefore, considering BLT in capacity calculation is necessary to avoid overestimation of BRT system capacity. 


\section{References}

Aashtiani, H., and H. Iravani. 2002. "Application of Dwell Time Functions in Transit Assignment Model." Transportation Research Record, 1817: 88-92.

Carey, N. G. 2002. "Applicability of Bus Rapid Transit to Corridors with Intermediate Levels of Transit Demand." Journal of Public Transportation 5(2): 97-107.

Curie, G. 2005. "The Demand Performance of Bus Rapid Transit." Journal of Public Transportation, 8(1): 41-55

Curie, G., A. Delbosc, S. Harrison, and M. Sarvi. 2013. "Impact of Crowding on Streetcar Dwell Time." Transportation Research Record, 2353: 100-106.

Deng, T., and J. D. Nelson. 2011. "Recent Developments in Bus Rapid Transit: A Review of the Literature." Transport Reviews, 31(1): 69-96.

Dueker, K. J., T. J. Kimpel, and J. G. Strathman. 2004. "Determinants of Bus Dwell Time." Journal of Public Transportation, 7(1): 21-39.

Feder R. 1973. The Effect of Bus Stop Spacing and Location on Travel Time. Pittsburgh: Carnegie Mellon University.

Guenthner, R. P., and K. C. Sinha. 1983. "Modeling Bus Delays Due to Passenger Boardings and Alightings." Transportation Research Record, 915: 7-13.

Guenthner, R. P., and K. Hamat. 1988. "Transit Dwell Time under Complex Fare Structure." Journal of Transportation Engineering, 114(3): 367-379

Gupta, M. Rajeev. 2014. Project Management. PHI Publications.

Jaiswal, S., J. Bunker, and L. Ferreira. 2010. "Influence of Platform Walking on BRT Station Bus Dwell Time Estimation: Australian Analysis." Journal of Transportation Engineering, 136(12): 1173-1179.

Jaiswal, S., J. Bunker, and L. Ferreira. 2010. “Modelling Bus Lost Time: An Additional Parameter Influencing Bus Dwell Time and Station Platform Capacity at a BRT Station." TRB 89th Annual Meeting Compendium of Papers.

Jiang, Y., P. C. Zegras, and S. Mehndiratta. 2012. "Walk the Line: Station Context, Corridor Type and Bus Rapid Transit Walk Access in Jinan, China." Journal of Transport Geography, 20(1): 1-14.

Larrain, H., and J. C. Munoz. 2008. "Public Transit Corridor Assignment Assuming Congestion Due to Passenger Boarding and Alighting. National Spatial Economics, 8: 241-256.

Levine, J., and G. Torng. 1994. "Dwell-Time Effects of Low-Floor Bus Design." Journal of Transportation Engineering: 914-929.

Levinson, H. S. 1983. "Analyzing Transit Travel Time Performance." Transportation Research Record, 915: 1-6.

Levinson, H. S., S. Zimmerman, and S. C. Rutherford. 2002. "Bus Rapid Transit: An Overview." Journal of Public Transportation, 5(2): 1-30. 
Lin, T., and N. H. Wilson. 1992. "Dwell Time Relationships for Light Rail Systems." Transportation Research Record, 1361: 287-295.

Mahadevia, D., R. Joshi, and A. Datey. 2012. "UNEP RISO Centre Report on Low-Carbon Mobility in India and the Challenges of Social Inclusion: Bus Rapid Transit (BRT) Case Studies in India."

Rajbhandari, R., S. Chien, and J. Daniel. 2003. "Estimation of Bus Dwell Times with Automatic Passenger Counter Information." Transportation Research Record, 1841: 120-127.

Satiennam T., S. Jaensirisak, W. Satiennam, and S. Detdamrong. 2013. "Potential for Modal Shift towards Bus Rapid Transit (BRT) in an Asian Developing City." Proceedings of Eastern Asia Society for Transportation Studies.

Sun, L., A. Tirachini, K. W. Axhausen, A. Erath, and L. Der-Horng. 2014. "Models of Bus Boarding and Alighting Dynamics." Transportation Research Part A, 69: 447-460.

Tang, L. M., F. Zhao, L. F. Chow, H. Zhang, and S. C. Li. 2006. "Simulation Model for Estimating Bus Dwell Time by Simultaneously Considering Numbers of Disembarking and Boarding Passengers." Transportation Research Record, 1971: 59-65.

Tirachini, A. 2013. "Estimation of Travel Time and the Benefits of Upgrading the Fare Payment Technology in Urban Bus Services." Transportation Research Part C: Emerging Technologies, 30: 239-256.

Transportation Research Board. 2003. Transit Capacity and Quality of Service Manual, 2nd Edition. Washington, DC.

Transportation Research Board. 2013. Transit Capacity and Quality of Service Manual, 3rd Edition. Washington, DC.

Vuchic, V. 2002. "Bus Semirapid Transit Mode Development and Evaluation." Journal of Public Transportation, 5(2): 71-95.

Vuchic, V. 2005. Urban Transit: Systems and Technology. Hoboken, NJ: John Wiley.

Zimmerman, S., and O. P. Agarwal. 2012. "International Experience in Bus Rapid Transit (BRT) Implementation: Synthesis of Lessons Learned from Lagos, Johannesburg, Jakarta, Delhi, and Ahmedabad." World Bank Report, 1-67.

\section{About the Authors}

ANKIT KATHURIA (writetokathuria@gmail.com) is a Civil Engineering graduate with post-graduate studies in Transport Planning. He is pursuing doctoral research at the Indian Institute of Technology (IIT) Roorkee. His research interests include public transportation, activity based modeling, and traffic engineering.

Dr. Manoranjan Parida (mparida@gmail.com) is a Professor in the Civil Engineering Department and Dean of Sponsored Research \& Industrial Consultancy at IIT Roorkee. Among his areas of research specialization are urban transportation 
planning and traffic safety. He has contributed more than 330 research papers/articles to international journals and conference proceedings and has published chapters in two books.

Dr. Ch. Ravi Sekhar (chalumuri.ravisekhar@gmail.com) is a Senior Scientist in Central Road Research Institute, India and has a 12 years professional experience in traffic and transportation engineering. He is involved in various in-house R\&D projects, CSIR core network projects, sponsored and consultancy projects undertaken by the Institute. His primary research includes mode choice analysis using neural networks and multinomial models, GIS application for rural road network planning, economic evaluation of rural road networks, route travel time estimation using traditional data and intelligent transportation systems (ITS) data, measuring travel time reliability of road transportation system, transport network assignment modeling, stochastic simulation modeling for travel time distribution under various uncertainties, and influence of supply side, demand and external of factors of road transportation system.

MANU PATHAK (manu.pathak.bplan12@cept.ac.in) is a fourth-year student working toward a bachelor's degree in Planning at CEPT University in Ahmedabad. He completed an internship at IIT Roorkee and was part of the student exchange program at Cardiff University in Wales. 